\title{
Sebastian Kopf: Web Editor
}

\author{
Jón Karlsson · Rene Verdonk • Roland Becker • \\ Neil P. Thomas
}

Published online: 20 October 2011

(C) Springer-Verlag 2011

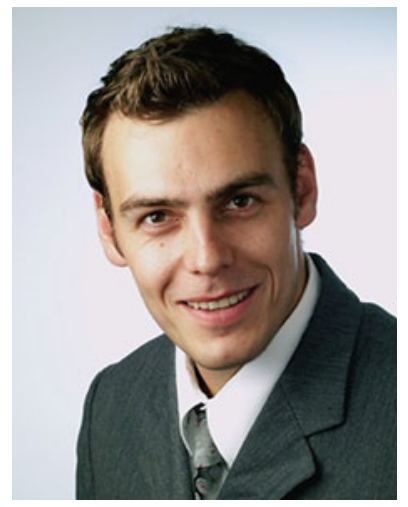

Sebastian Kopf, M.D., has been appointed Web Editor of Knee Surgery Sports Traumatology Arthroscopy (KSSTA) effective from January 2012.

Sebastian has served the journal for several years as a reviewer.

Sebastian started his training at the Department of Orthopaedic Surgery at the Otto-von-Guericke University of Magdeburg in Germany under the leadership of

Prof. H.-W. Neumann. He defended his doctoral thesis on "The Effect of Locally Applied Vascular Endothelial Growth Factor on Meniscal Healing" at the Department of Orthopaedic Surgery of the Otto-von-Guericke University Magdeburg in 2007.

He spent 2 years, one as an AGA fellow at the Department of Orthopaedic Surgery in Pittsburgh, USA, under the leadership of Prof. Freddie H. Fu.

His research work focuses mainly on anatomy and biomechanics of the ACL and the meniscus and its surgical techniques as well as on knee kinematics and stem cell treatment.

Back in Germany, he continued his residency at the Charité, Center for Musculoskeletal Surgery in Berlin in Germany under the leadership of Prof. N. P. Haas. Sebastian is interested in sports traumatology with special focus on knee surgery.

Sebastian has been a member of ESSKA since 2007, member of ISAKOS, committee member of AGA, international member of ORS as well as AAOS.

Sebastian is a very active and enthusiastic young orthopaedic surgeon and we welcome him as a Web Editor for KSSTA.

J. Karlsson $(\bowtie)$

Department of Orthopaedics, Sahlgrenska University Hospital,

Gothenburg, Sweden

e-mail: jon.kssta@gmail.com

R. Verdonk

Department of Orthopaedics and Traumatology,

Ghent State University, Ghent, Belgium

R. Becker

Department of Orthopaedic and Traumatology,

City Hospital Brandenburg, Hochstrasse 29,

14770 Brandenburg/Havel, Germany

N. P. Thomas

Winchester, UK 